\title{
Three-dimensional mantle lithosphere deformation at collisional plate boundaries: A subduction scissor across the South Island of New Zealand
}

\author{
() R. Pysklywec ${ }^{1}$, S. Ellis², A. Gorman ${ }^{3}, 2010$ \\ ${ }^{1}$ Department of Geology, University of Toronto, Toronto, Ontario Canada \\ russ@geology.utoronto.ca \\ ${ }^{2}$ Institute of Geological and Nuclear Sciences, Lower Hutt, New Zealand \\ S.Ellis@gns.cri.nz \\ ${ }^{3}$ Department of Geology, University of Otago, Dunedin, New Zealand \\ andrew.gorman@otago.ac.nz
}

The continental plate collision across the South Island of New Zealand is highly oblique (dextral) and is bounded by oppositely verging ocean plate subduction zones - with north-west dipping Hikurangi subduction to the north and east-dipping FiordlandPuysegur subduction to the south [e. g.; Okaya et al., 2007; and references therein]. As such, the region can be considered as a type of "subduction scissor". Within this tectonic context, we use three dimensional computational geodynamic models to consider how convergent mantle lithosphere can be modified by scissor and strike-slip effects. Bounding subduction at both ends of the continental collision causes flow of the descending mantle lithosphere in the direction along-strike of the model plate boundary, with thinning in the centre and thickening towards the subduction zones that bifurcates the continental mantle lithosphere root. With dipping bounding subduction, the mantle lithosphere root takes on a more complex morphology that folds over from one subduction polarity to the other, but remains as a continuous feature as it folds under the collision zone (Figure). In the absence of bounding subduction, the plate convergence causes a linear (along-strike) mantle lithosphere root to develop. A rapid strike-slip motion between the converging plates transfers material in the plate boundary-parallel direction and tends to blur out features that develop in this direction - such as descending viscous instabilities. The along-strike variations in the morphology of the mantle lithosphere root that develop in the models - viz., thickening of the root towards the subduction edges, thinning in the center - are consistent with recent, albeit poorly constrained, geophysical interpretations of the largescale lithospheric structure of the South Island [Kohler, Eberhart-Phillips, 2002; Scherwath et al., 2006]. We speculate that this reflects the nature of the evolution of the South Island collision as a limited continental segment of the plate boundary that it is dominated and guided by adjacent well-developed/developing ocean plate subduction. The modelling provides insights into how varying "three-dimensional effects" could influence the evolution of the continental mantle lithosphere at the South Island and may have implications for understanding other collisional zones where a continental plate ends or transitions into ocean plate subduction. 


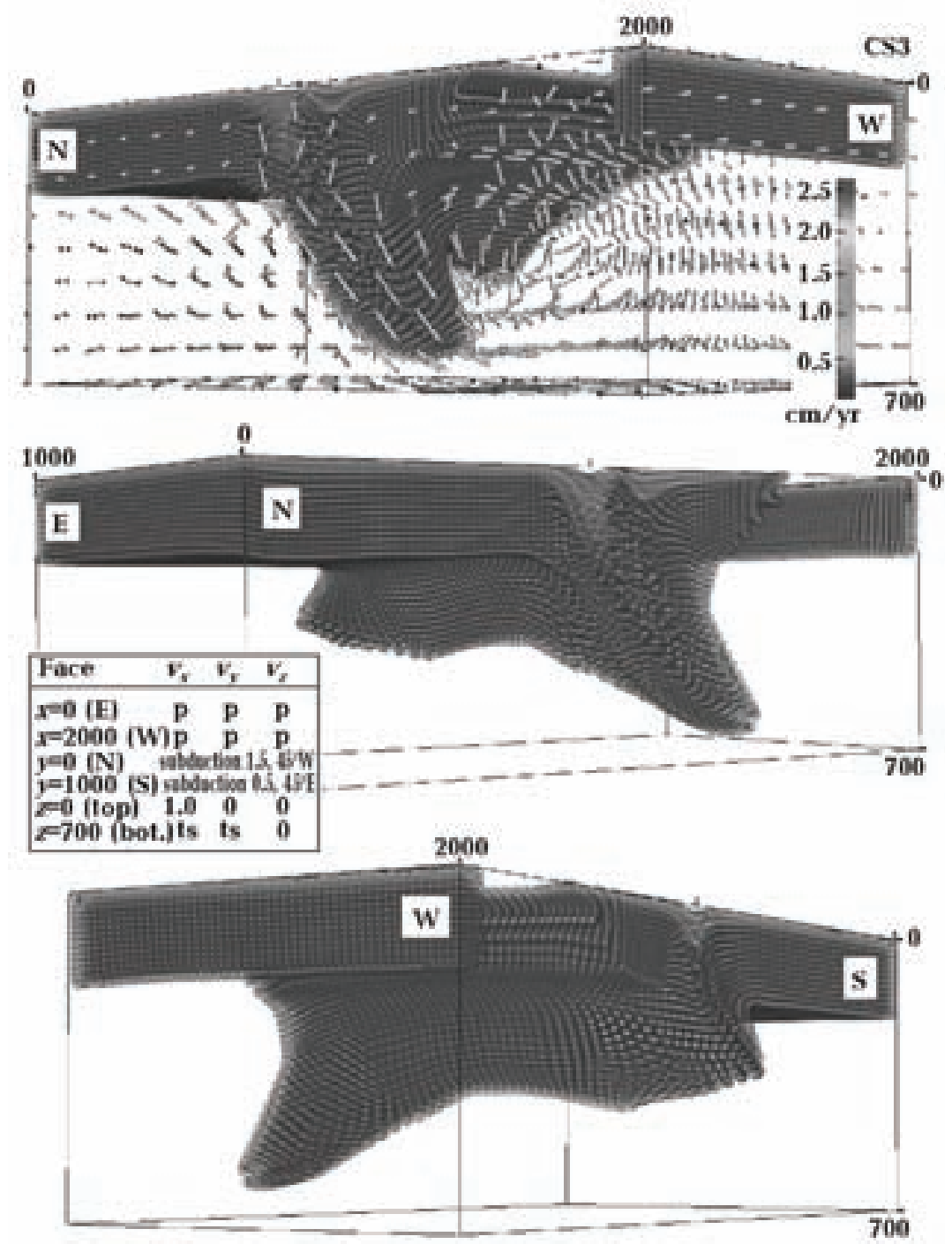

Model CS3 at 29 Myr. Three views of the inverted anvil-type morphology of the mantle lithosphere (marked distances in km). Inset table indicates velocity boundary conditions on the six surfaces of the box. The locations of the faces are indicated by intercepts of the planes as well as their corresponding compass direction in the convention adopted here. The velocity magnitudes are in $\mathrm{cm} / \mathrm{yr}$ and indicate the total magnitude for the spatially variable boundary conditions on the individual faces; ' $p$ ' refers to a periodic boundary condition, 'fs' refers to free slip.

\section{References}

Kohler M., Eberhart-Phillips D. Three-dimensional lithospheric structure below the New Zealand Southern Alps // Geophys. J. Res. - 2002. - 107.

Okaya D., Stern T., Davey F., Henrys S., Cox S. Continent-continent collision at the Pacic/Indo-Australian plate boundary: back- ground, motivation, and principal results / Eds. D. A. Okaya, T. A. Stern,
F. J. Davey. A continental plate boundary: tectonics at South Island, New Zealand // Amer. Geophys. Union. - 2007. - 175. - P. 1-18.

Scherwath M., Stern T., Davey F., Davies R. Three-dimensional lithospheric deformation and gravity anomalies associated with oblique continental collision in South Island, New Zealand // Geophys. J. Int. -2006 . -167. 